\title{
ANALISIS USAHATANI SAYURAN ORGANIK (Studi Kasus di Desa Selacai Kecamatan Cipaku Kabupaten Ciamis)
}

\author{
ADITYA PERMANA $\mathbf{R}^{1}$ *, DINI ROCHDIANI ${ }^{2}$, BUDI SETIA ${ }^{1}$ \\ ${ }^{1}$ Fakultas Pertanian Universitas Galuh \\ ${ }^{2}$ Fakultas Pertanian Universitas Padjajaran \\ *E-mail : aditrahman66@gmail.com
}

\begin{abstract}
ABSTRAK
Penelitian ini bertujuan untuk menganalisis biaya dan pendapatan usahatani sayuran organik di Kelompok Wanita Tani Desa Selacai.Jenis sayuran organik yang diusahakan oleh Kelompok Wanita Tani ini adalah bayam, kangkung, dan caisim.Metode penelitian yang digunakan dalam penelitian ini adalah studi kasus.Data diperoleh dari hasil wawancara dengan wanita tani yang diambil secara sensus terhadap 5 orang wanita tani. Hasil penelitian ini memperlihatkan bahwa ; (1) Biaya produksi rata-rata per hektar per musim tanam yang digunakan dalam usahatani sayuran organik untuk kangkung yaitu Rp. 1.295.900,-, bayam Rp. 1.249.000,- dan caisim Rp.1.239.600,-. ; (2) Penerimaan wanita tani ratarata per hektar per musim tanam dalam usahatani sayuran organik untuk kangkung yaitu Rp. 3.090.000,-, bayam Rp.2.072.000,- dan untuk caisim Rp. 2.610.000,-;(3)Pendapatan wanita tani ratarata per hektar per musim tanam dari usahatani sayuran organik untuk kangkung adalah Rp. 1.794.100,-, bayam Rp.823.000,-, dan caisim Rp. 1.370.400,-. Pendapatan tertinggi diperoleh dari sayuran organik kangkung.; (4)Imbangan Penerimaan dan biaya (R/C) untuk semua jenis sayuran organik lebih besar dari 1, yaitu rata-rata 2,05, artinya setiap satu satuan rupiah pengeluaran atau biaya untuk usahatani sayuran organik, akan menghasilkan penerimaan Rp.2,05 dan pendapatan Rp.1,05 dan dapat dikatakan usahatani sayuran organik layak diusahakan karena menguntungkan bagi para petani umumnya dan khususnya para wanita tani di Desa Selacai Kecamatan Cipaku Kabupaten Ciamis.
\end{abstract}

Kata kunci: Usahatani, Sayuran, Organik.

\section{PENDAHULUAN}

Pasokan produk hortikultura nasional dapat memenuhi kebutuhan konsumen dalam negeri, baik melalui pasar tradisional, pasar modern, maupun pasar luar negeri (Direktorat Jenderal Hortikultura, 2011). Salah satu komoditi hortikultura yang memiliki potensi besar untuk dikembangkan adalah sayuran organik. Sayuran organik memiliki potensi yang baik dilihat dari nilai ekonomi, aman dikonsumsi,dan kandungan nutrisi yang tinggi untuk kesehatan manusia.
Pranasari (2007) menjelaskan bahwa pada umumnya, produk sayuran organik memang tidak mudah ditemui.sesuai target pasarnya, produk ini tersedia di supermarket dan agen khusus produk pertanian organik..Berikut ini data produksi sayuran di Indonesia dari tahun 2015 sampai 2018.

Desa Selacai merupakan salah satu wilayah sentra produksi sayuran organik di Kabupaten Ciamis yang mempunyai potensi untuk dikembangkan, karena memiliki peranan penting bagi masyarakat dalam memenuhi kebutuhan pangan 
sehari-hari.Jenis sayuran organik yang diusahakannya yaitu bayam, kangkung dan caisim.Tahun 2018 di Desa Selacai telah menghasilkan produksi sayuran organik yang baik, dimana produksi sayuran tertinggi adalah caisim, sedangkan produksi terendah adalah kangkung.Berikut data produksi sayuran di Desa Selacai tahun 2018.

Usahatani sayuran organik ini di Desa Selacai dilakukan oleh para wanita tani yang tergabung dalam Kelompok Wanita Tani (KWT) Desa Selacai Kecamatan Cipaku Kabupaten Ciamis. Para wanita tani ini melakukan kegiatan usahatani sayuran organik dengan harapan agar memperoleh pendapatan yang bisa untuk membantu memenuhi kebutuhan hidupnya, Walaupun biaya produksi untuk usahatani sayuran organik ini tinggi, tetapi para wanita tani dapat menjualnya dengan tanpa rugi yaitu antara Rp.5.000 - Rp. 10.000/kg dibanding harga sayuran bukan organik yang masih lebih rendah ( $\mathrm{Rp}$. 2.000)Bila harga sayuran organik tinggi dan produksinya diikuti dengan kualitas yang baik, maka para wanita tani akan memperoleh penerimaan dari usahatani sayuran organiknya tinggi. Demikian pula, jika dalam penggunaan biaya produksinya rendah, maka para wanita tani dapat memperoleh pendapatan yang tinggi yang dapat digunakan untuk memenuhi kebutuhan sehari-hari di keluarganya.Berdasarkan uraian diatas menarik untuk diteliti mengenai Analisis Usahatani Sayuran Organik yang dilakukan oleh Kelompok Wanita Tani di Desa Selacai, Kecamatan Cipaku Kabupaten Ciamis.

\section{METODE PENELITIAN}

\section{Jenis Penelitian}

Penelitian yang digunakan adalah studi kasus, dengan mengambil kasus pada kelompok wanita tani sayuran organik di Desa Selacai Kecamatan Cipaku Kabupaten Ciamis.Menurut Arikunto (2010) studi kasus adalah penelitian yang dilakukan secara intensif terinci dan mendalam terhadap suatu organisasi, lembaga atau gejala tertentu.Ditinjau dari wilayahnya, maka penelitian kasus hanya meliputi daerah atau subyek yang sempit, tetapi ditinjau dari sifat penlitian, penelitian kasus lebih dalam.

\section{Teknik Pengumpulan Data}

Data primer merupakan data yang diperoleh langsung dari lapangan oleh orang yang melakukan penelitian atau yang bersangkutan yang memerlukannya.Data primer dilakukan melalui wawancara dan pengamatan 
langsung dengan petani sayuran organik.Data sekunder adalah data yang diperoleh atau dikumpulkan oleh orang yang melakukan penelitian dari sumbersumber yang telah ada, biasanya diperoleh dari instansi terkait (Hasan, Iqbal, 2008).Data sekunder untuk penelitian ini diperoleh dari studi literatur, laporanlaporan, pustaka dan lembaga/instansi yang terkait dalam penelitian ini.Data sekunder dapat diperoleh juga melalui dokumen, dapat berupa informasi tentang kondisi geografis seperti letak, luas, batas, iklim, dan data demografis. Data sekunder diperoleh dari Dinas terkait dan berdasarkan pengamatan di lapangan.

\section{Teknik Penarikan Sampel}

Pengambilan sampel dalam penelitian ini diambil secara sensus terhadap 5 orang wanita tani yang melakukan usahatani sayuran organik di Desa Selacai.Seluruh wanita tani ini tergabung dalam Kelompok Wanita Tani (KWT) sayuran organik Desa Selacai.

\section{Rancangan Analisis Data}

\section{Analisis Penerimaan}

Menurut Suratiyah (2006), secara umum perhitungan penerimaan total (Total Revenue/TR) adalah perkalian antara jumlah peoduksi (Y) dengan harga jual
(Py) dan dinyatakan dengan rumus sebagai berikut:

$\mathrm{TR}=\mathrm{Y}$. Py

Dimana:

$\mathrm{TR}=$ Total Revenue (Penerimaan total)

$\mathrm{Y}=$ Produksi yang diperoleh

Py = Harga

2. Analisis Pendapatan

Menurut Suratiyah (2006), pendapatan adalah selisih antara penerimaan (TR) dengan biaya total (TC) dan dinyatakan dengan rumus:

$\mathrm{Pd}=\mathrm{TR}-\mathrm{TC}$

Dimana:

$\mathrm{Pd}=$ Pendapatan

$\mathrm{TR}=$ Total revenue (Penerimaan total $)$

$\mathrm{TC}=$ Total cost $($ Biaya Total $)=$

Total cost (Biaya Total)

3. Analisis R/C

Menurut Suratiyah (2006), R/C adalah perbandingan antar penerimaan dengan biaya total, dinyatakan dengan rumus:

$\mathrm{R} / \mathrm{C}=\frac{\text { Penerimaan Total }}{\text { Biaya Total }}$

Hasil analisis tersebut dapat dilihat berapa jumlah penerimaan yang akan diperoleh petani dari setiap rupiah yang dikeluarkan petani dalam usahatani sayuran organik tersebut, dengan ketentuan sebagai berikut:

(a) R/C > 1, bahwa usahatani
sayuran organik
menguntungkan.


(b) $\mathrm{R} / \mathrm{C}=1$, maka usahatani sayuran organik tersebut tidak untung tidak rugi.

(c) $\mathrm{R} / \mathrm{C}<1$, maka usahatani tersebut rugi.

\section{Tempat dan Waktu Penelitian}

Penelitian inidilaksanakan di Desa Selacai Kecamatan Cipaku Kabupaten Ciamis dengan pertimbangan bahwa wilayah tersebut merupakan sentra produksi sayuran organik di Kabupaten Ciamis.Waktu penelitian dibagi dalam tahapan sebagai berikut:

1) Tahapan persiapan yaitu survei pendahuluan, penulisan Usulan Penelitiandan Seminar Usulan Penelitian direncanakan pada bulan Maret 2019.

2) Tahapan pengumpulan data dari lapangan, yaitu pengumpulan data primer dan data sekunder direncanakan pada bulan April 2019.

Tahapan pengolahan dan analisis data, penyusunan serta penulisan Usulan Penelitian direncanakan pada bulan Mei 2019 sampai dengan selesai.

\section{HASIL DAN PEMBAHASAN}

\section{Identitas Responden}

\section{Umur Respon}

Umur adalah faktor yang mempengaruhi terhadap keberhasilan dalam melakukan sutau kegiatan usaha dan juga akan berpengaruh terhadap kemampuan fisik dalam bekerja dan cara berfikir. Umur para wanita tani yang melakukan usahatani sayuran organik yaitu berusia 20 sampai 47 tahun. Ini tergolong padausia produktif.

\section{Keadaan Pendidikan}

Ini menentukan terhadap seseorang dalam melaksanakan kegiatan usaha, karena dalam pola pikir orang yang berpendidikan rendah sangat berbeda jauh dengan orang yang berpendidikan lebih tinggi, sehingga dalam penerimaan hal-hal yang baru lebih sulit bagi yang berpendidikan rendah, dalam suatu usaha juga ditentukan pula apakah orang tersebut bisa mengelola dengan baik atau tidak. Pengelola Usahatani sayuran organik yang berada di Desa Selacai Kecamatan Cipaku Kabupaten Ciamis rata-rata tamatan SLTA, Oleh sebab itu usaha tersebut dapat beroperasi dengan baik hingga berkembang dan menghasilkan keuntungan, dan ilmu yang didapatkan dapat diaplikasikan dengan baik.

\section{Pengalaman Berusaha}


Usahatani sayuran organik yang dilakukan para petani di Desa Selacai ratarata sudah berjalan selama 2 tahun, hal tersebut merupakan modal utama untuk lebih terampil dalam mengatasi kesulitankesulitan maupun hambatan-hambatan yang mungkin terjadi saat usaha tersebut berlangsung.

\section{Tanggungan Keluarga}

Banyaknya tanggungan keluarga akan berpengaruh terhadap tingkat kesejahteraan keluarga. Banyaknya jumlah anggota keluarga yang menjadi tanggungan para petani sayuran organik di Desa Selacai rata-rata 4 orang.

\section{Usahatani Sayuran Organik}

\section{Persiapan Lahan}

Persiapan lahan merupakan tahap pertama yang harus dilakukan agar lahan pertanian layak untuk ditanami sayuran organik.

\section{b. Pembibitan}

Bibit sayuran organik yang ditanam petani pada daerah penelitian didapat dengan cara membeli dari KUD maupun menyemai bibit sendiri.

c. Penanaman

Penanaman sayuran berarti memindahkan bibit dari tempat persemaian ke lahan pertanian.Adapun beberapa jenis sayuran berbeda dalam penanganannya.

d. Pemeliharaan tanaman

1) Penyulaman

Penyulaman merupakan pengecekan dan penanaman kembali pada tanam dinilai tidak sehat. Penyulaman sayuran dilakukan dengan cara menggantikan tanaman yang mati atau tidak sehat, agar lubang taman yang telah diberi pupuk organik oleh petani tidak sia-sia dan memaksimalkan hasil panen.

2) Penyiangan, pengairan, dan pemupukan

Penyiangan merupakan proses pengairan yang dilakukan menggunakan ember dan proses penggemburan tanah dengan cangkul. Setiap sayuran mempunyai waktu yang berbeda-beda dalam proses penyiangannya. Untuk tanaman Caisim, penyiangan dilakukan secara manual 2 minggu sekali atau sesuai pertumbuhan gulma, biasanya penyiangan dan penggembutan dilakukan sekaligus untuk menghemat tenaga kerja. Penyiangan pada tanaman kangkung dilakukan setiap 2 atau 3 minggu dengan menambahkan pupuk kandang di samping tanaman 
dengan jarak 1 jengkal $/ 15 \mathrm{~cm}$. Tanaman caisim membutuhkan penyiraman secara teratur, terutama pada musim kemarau penyiangan dapat dilakukan 2.4 kali selama masa penanaman. Pemupukan tambahan pada saat 3 musim tanam dengan pemberian pupuk kandang $500 \mathrm{~kg} / \mathrm{ha}$ dengan cara dicampur pada tanah yang akan dijadikan media tanam.

\section{e. Pengendalian hama penyakit}

pada usahatani sayuran organik sama sekali tidak menggunakan obat-obatan kimia. Para petani hanya menggunakan tanaman yang berguna untuk mengusir lalat dan hama lainnya.

\section{Analisis Biaya Usahatani Sayuran Organik}

\section{Biaya Total}

Biaya yang digunakan dalam usahatani sayuran organic dibagi menjadi dua jenis biaya, yaitu biaya tetap dan biaya variabel.Biaya tetap yaitu biaya yang besar kecilnya tidak dipengaruhi oleh besar kecilnya produksi, yang terdiri dari penyusutan alat, pajak bumi dan bangunan, izin usaha, NPWP dan Bunga Modal. Sedangkan biaya variabel adalah biaya yang besar kecilnya dipengaruhi oleh besar kecilnya produksi, yang terdiri dari biaya penyediaan bahan baku (sarana produksi), dan tenaga kerja.

Tabel 1. Rincian Biaya Total Usahatani Sayuran Organik

\begin{tabular}{|c|c|c|c|c|c|c|c|c|c|}
\hline \multirow{3}{*}{$x_{0}$} & \multicolumn{3}{|c|}{ Kaselatiog } & \multirow{2}{*}{\multicolumn{3}{|c|}{ Alvas }} & \multicolumn{3}{|c|}{ Conin } \\
\hline & \multicolumn{3}{|c|}{ 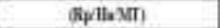 } & apthasm) & & & \multicolumn{3}{|c|}{ (Rpplisum) } \\
\hline & $\bar{N}$ & II & IPI & 䨗 & BT & EFI & BN & IIF & BPI \\
\hline 1 & 136520 & 15 & $13 \pi 90$ & 1280090 & 1 & $13 \mid 00$ & 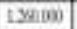 & 2 & $11 \sin 20$ \\
\hline 2 & 14580 & 1.5 & 135000 & I.X650) & : & 13ELON & $12 * 00$ & 2 & $13 \$ 2000$ \\
\hline 3 & 1310300 & 15 & $12 \pi 50$ & $1 \times 8 \times 00$ & 1 & $13 x+000$ & tyoned & 2 & $1352 a 0$ \\
\hline 4 & 130650 & 15 & $12 \pi, 00$ & $1185 \times 90$ & 2 & IKLON & HWw & 2 & 116290 \\
\hline 5 & $1316: 00$ & 15 & $130+520$ & 124900 & 2 & 13ation & 1350000 & 2 & 136290 \\
\hline 2 & G.9.m & 75 & 6499.5 & 6.235 .001 & 18 & 634ace & $6168=9$ & If & 6.194. \\
\hline$x$ & 1.594 .490 & 15 & L2969: & 1.247 .901 & 2 & 1189.96 & 1.237 .99 & 2 & 1.25960 \\
\hline
\end{tabular}

\section{Analisis Penerimaan , Pendapatan dan}

\section{R/C Kremes}

Penerimaan wanita tani rata-rata per hektar per musim tanam dalam usahatani sayuran organik untuk kangkung yaitu Rp. 3.090.000,-, bayam Rp.2.072.000,- dan caisim Rp. 2.610.000,-

Pendapatan wanita tani rata-rata per hektar per musim tanam dari usahatani sayuran organik untuk kangkung adalah Rp. 1.794.100,-, bayam Rp.823.000,-, dan caisim Rp. 1.370.400,-. Pendapatan tertinggi diperoleh dari sayuran organik kangkung.

Imbangan Penerimaan ( $\mathrm{R})$ dan biaya ( $\mathrm{C}$ ) atau $\mathrm{R} / \mathrm{C}$ untuk semua jenis sayuran organik adalah lebih besar dari 1 yaitu rata-rata 2,05, artinya setiap satu satuan rupiah pengeluaran atau biaya untuk usahatani sayuran organik , akan menghasilkan penerimaan Rp.2,05 dan pendapatan Rp.1,05 dan dapat dikatakan usahatani sayuran organik layak diusahakan karena menguntungkan bagi 
para petani umumnya dan khususnya para wanita tani di Desa Selacai Kecamatan Cipaku Kabupaten Ciamis.

Tabel 11. Luas lahan dan Jumlah Produksi Sayuran Organik (Kg/Hektar/ Musim Tanam)

\begin{tabular}{|c|c|c|c|c|}
\hline No & $\begin{array}{c}\text { Luas } \\
\text { Lahan } \\
\text { (Ha) }\end{array}$ & $\begin{array}{c}\text { Kangkung } \\
\text { Kg/Hektar } \\
\text { / Musim } \\
\text { Tanam) }\end{array}$ & $\begin{array}{c}\text { Bayam } \\
\text { (Kg/Hektar } \\
\text { / Musim } \\
\text { Tanam) }\end{array}$ & $\begin{array}{c}\text { Caisim } \\
\text { Kg/Hektar } \\
\text { / Musim } \\
\text { Tanam) }\end{array}$ \\
\hline 1 & 0,1 & 320 & 270 & 285 \\
\hline 2 & 0,1 & 310 & 260 & 295 \\
\hline 3 & 0,1 & 325 & 275 & 300 \\
\hline 4 & 0,1 & 300 & 250 & 300 \\
\hline 5 & 0,1 & 290 & 240 & 270 \\
\hline $\mathbf{Z}$ & $\mathbf{0 , 5}$ & $\mathbf{1 . 5 4 5}$ & $\mathbf{1 . 2 9 5}$ & $\mathbf{1 . 4 5}$ \\
\hline $\mathbf{X}$ & $\mathbf{0 , 1}$ & $\mathbf{3 0 9}$ & $\mathbf{2 5 9}$ & $\mathbf{2 9 0}$ \\
\hline
\end{tabular}

\section{KESIMPULAN DAN SARAN}

\section{Kesimpulan}

1) Biaya produksi rata-rata per hektar per musim tanam yang digunakan dalam usahatani sayuran organik untuk kangkung yaitu Rp. 1.295.900,-, bayam Rp. 1.249.000,- dan caisim Rp.1.239.600,-.

2) Penerimaan wanita tani rata-rata per hektar per musim tanam dalam usahatani sayuran organik untuk kangkung yaitu Rp. 3.090.000,-, bayam Rp.2.072.000,- dan caisim Rp. 2.610.000,-

3) Pendapatan wanita tani rata-rata per hektar per musim tanam dari usahatani sayuran organik untuk kangkung adalah Rp. 1.794.100,-, bayam Rp.823.000,-, dan caisim Rp. 1.370.400,--. Pendapatan tertinggi diperoleh dari sayuran organik kangkung.

4) Imbangan Penerimaan ( $R$ ) dan biaya ( C ) atau R/C untuk semua jenis sayuran organik adalah lebih besar dari 1 yaitu rata-rata 2,05, artinya setiap satu satuan rupiah pengeluaran atau biaya untuk usahatani sayuran organik, akan menghasilkan penerimaan Rp.2,05 dan pendapatan Rp.1,05 dan dapat dikatakan usahatani sayuran organik layak diusahakan karena menguntungkan bagi para petani umumnya dan khususnya para wanita tani di Desa Selacai Kecamatan Cipaku Kabupaten Ciamis..

\section{Saran}

Untuk meningkatkan pendapatan dalam kegiatan usahatani sayuran organik diharapkan para wanita tani melakukan usahatani sayuran organik dengan cara meningkatkan intensitas dalam usahataninya dan juga melakukan kegiatan usahatani sayuran organik sesuai standard operasional procedure (SOP)agar lebih menguntungkan.

\section{DAFTAR PUSTAKA}

Achmadi, E.E. 2011. Organik Vs Non Organik. http://www.femina.co.id. Diakses pada tanggal 20 Mei 2016

Alma, Buchari. 2003. Kewirausahaan. Penerbit Alfabeta. Bandung

Annisa, Febri dan Leni. 2016. Urban Farming Bertani Kreatif Sayur, Hias, 
dan Buah. Agriflo (Penebar Swadaya Grup). Jakarta.

Arianti, Y,S., Kusnandar, Utami BW. 2015. Strategi Pengembangan Agribisnis Bayam Jepang Organik Di Desa Batur, Kecamatan Getasan, Kabupaten Semarang. AGRISTA Vol 3 (3): 387 - 399. http://jurnal.fp.uns.ac.id/index. php/agrista/article/view/644. Diakses pada tanggal 10 April 2016.

Fadholi, H. 1991. Ilmu Usaha Tani. Penebar Swadaya. Jakarta.

Gunadi.2001. Restrukturisasi Perusahaan Dalam Berbagai Bentuk dan Pemajakannya. Salemba Empat. Jakarta.

Hadi, P.U., Mayrowani, H., Supriyati dan Sumedi. 2000. Review and Outlook

Pengembangan Komoditas Hortikultura. Seminar Nasional Perspektif Pembangunan Pertanian dan Kehutanan Tahun 2001 ke Depan. Pusat
Penelitian Sosial Ekonomi Pertanian.Badan Penelitian dan Pengembangan Pertanian. Bogor.

Hanafie, R. 2010. Pengantar Ekonomi Pertanian. ANDI Yogyakarta. Yogyakarta

Wahyuni, Y.T. 2007. Analisis Cabang Usahatani Sayuran Organik di Mega Surya Organic Kecamatan Mega Mendung, Kabupaten Bogor.Skripsi. Fakultas Pertanian. Institut Pertanian Bogor. Bogor.

Wiyanti AN. 2012. Implementasi Program Urban Farming Pada Kelompok Sumber Trisno Alami Di Kecamatan Bulak Kota Surabaya.e-Journal UNESA Vol 1 (2): 1-15.

Zulkarnain. 2009. Kultur Jaringan Tanaman, Solusi Perbanyakan Tanaman Budi Daya. Bumi Aksara. Jakarta.

Teknologi Industri. Manado. (https://fdokumen.com/document/kar ya-ilmiah-keripik-kelapaperbaikan.html). Diakses pada tanggal 16 juli 2019 .. 